Presented at the May 20-24, 2012, World Environmental and Water Resources Congress in Albuquerque, NM. http://www.itrc.org/papers/magmeter12.htm ITRC Paper No. P 12-006

\title{
Implementation of Magnetic Meters for Irrigation Volumetric Measurement
}

\author{
Stuart W. Styles ${ }^{1}$ and Lynn Groundwater ${ }^{2}$ \\ ${ }^{1}$ Professor, Cal Poly State University BioResource and Agricultural Engineering Dept. and Director, Irrigation \\ Training and Research Center. Phone: (805) 756-2429. Fax: (805) 756-2434. sstyles@calpoly.edu \\ ${ }^{2}$ Student Engineer, Cal Poly ITRC. Phone: (805) 756-2434. Fax: (805) 756-2434. 1groundw@calpoly.edu
}

\begin{abstract}
The irrigation industry is experiencing a growth in the use of magnetic meters for measuring the flow rate and volume in irrigation pipelines. Historically, propeller meters have been the device selected by users. New legislation in California (SB7x7) will require measurement devices at key locations for irrigation water delivery. Some users are very interested in the magnetic meter for making the measurement at the turnout or farm gate. The key feature of the new meter is the ability for the device to work in less than ideal flow conditions.

Electromagnetic meters have been tested by the Irrigation Training and Research Center in lab and field pipelines located less than the 10 diameters upstream of disturbances with good results. There are several manufacturers that are selling units to the irrigation market as well as several types of magnetic meter designs. This paper discusses how a magnetic flow meter works, advantages/disadvantages of this type of meter, test results, and new guidelines for field applications.
\end{abstract}

\section{INTRODUCTION}

\section{Background}

Magnetic meters have been available for a number of years. Historically, the main problem with using a magnetic meter was the cost. Units were sold at about $\$ 1,000$ per inch or approximately $\$ 12,000$ for a 12 -inch $(30.5 \mathrm{~cm})$ diameter pipe application. For agricultural applications, this cost was prohibiting widespread use of the meters. Currently, the demand for the magnetic meters has increased and prices have decreased significantly. The cost for a magnetic meter is quickly approaching the cost of the tradition measurement device for pipelines - the propeller meter.

Additionally, new regulations in California have prompted new interest in measurement devices that are both robust and accurate. SB7x7 bill is California legislation that pertains to agricultural water users and should be active in February 2012. The Department of Water Resources has adopted regulations that provide for a range of options that agricultural water suppliers may use, or implement, to comply with the requirement that suppliers measure the volume of water delivered to customers with sufficient accuracy and to submit an annual report to the department that summarizes aggregated farm-gate delivery data, on a monthly or bimonthly basis, using best professional practices (California Water Code 531.10(a)).

The Department of Water Resources requires the agricultural water suppliers to prepare and to adopt agricultural water management plans by December 31, 2012, to update those plans by December 3, 2015, and every 5 years thereafter. The agricultural water suppliers shall measure the volume of water delivered to customers, adopt a pricing structure for water customers based on the quantity delivered, and implement additional efficient managing 
practices. Agriculture water suppliers who do not meet the water management planning requirements established by this bill are not eligible for state water grants or loans, effective in 2013.

The accuracy and long-term success of any flow measurement program depends on many factors. Magnetic flow measurement is rapidly becoming the technique of choice in pipelines because of its simplicity and accuracy. However, the application of this technology has been limited in the past because of standard practice guidelines for magnetic flow meters, which required installing the meters in a straight section of pipe at least 8-10 pipe diameters from any source of turbulence. In addition, standard practice recommends having at least two pipe diameters of straight unobstructed pipe downstream from the meter. However, in the case of many irrigation pumping plants, turnouts, and deliveries, these conditions can rarely be met without extensive and expensive modifications. Therefore, the Irrigation Training and Research Center (ITRC) at Cal Poly State University, San Luis Obispo is currently investigating electromagnetic flow meters for potential applications under nonstandard conditions.

Several current manufacturers claim that their magnetic meters can perform well even in locations where only two diameter lengths of straight pipe are available. Testing was done by the ITRC on several magnetic meters at the Cal Poly Water Resources Facility to evaluate comments by the manufacturers and to make recommendations to irrigation districts and growers interested in this new technology.

Goals of this research:

- The accuracy of the magnetic meters in locations that are less than optimal

- The sensitivity of meters to increasing amounts of turbulence

Since this research was conducted, there have been numerous field installations of magnetic meters in various irrigation applications in California. In January 2012, the Shafter-Wasco Irrigation District installed 25 magnetic meters. The general manager reported that the magmeters have been installed and are performing well.

\section{Magnetic Meters Operating Principle}

According to Faraday's Law, a voltage will be induced proportional to the velocity of a conductor as it moves at right angles through a magnetic field. The water in the pipe is the conductor. By simply measuring the voltage, a magnetic meter is able to calculate the volume of the liquid passing through a controlled section.

\section{Faraday's Formula:}

$$
\begin{aligned}
& \mathbf{E} \text { is proportional to } \mathbf{V} \times \mathbf{B} \times \mathbf{D} \\
& \mathbf{E}=\text { The voltage generated in a conductor } \\
& \mathbf{V}=\text { The velocity of the conductor } \\
& \mathbf{B}=\text { The magnetic field strength } \\
& \mathbf{D}=\text { The length of the conductor }
\end{aligned}
$$

This principle works for irrigation water passing through the magnetic field generated by the magnetic meter since the water acts as the conductor. The basic operating principle for 
magnetic meters is illustrated in Figure 1. Note that this discussion is limited to full-bore or in-line magnetic meters. There are several other types of meters on the market but this type is the one that was evaluated. ${ }^{1}$

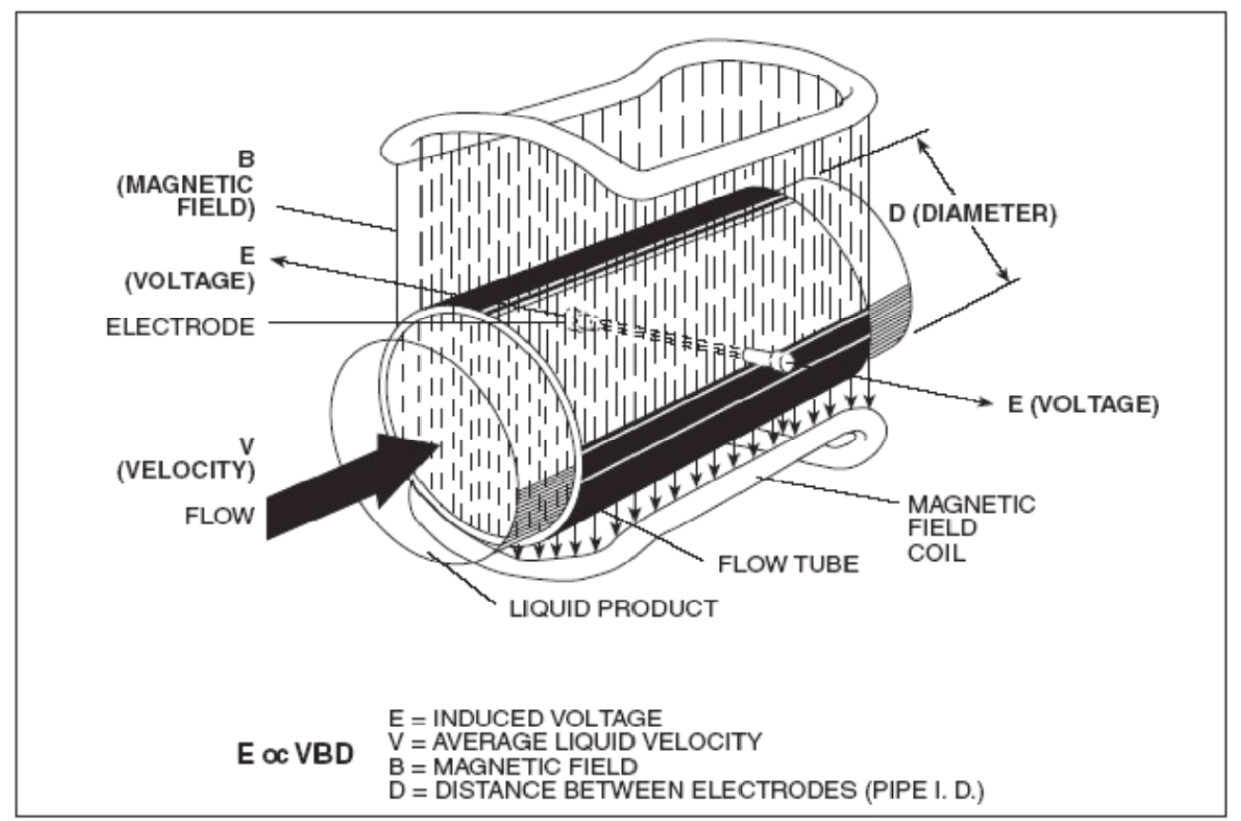

Figure 1. Operating principle for full-bore magnetic meter (Omega 2009)

As seen in Figure 2, there are two electrodes located inside the magnetic meter to measure the induced voltage. The flow rate/totalizer indicator is located on the top of the unit. These units can be placed at any angle. It is recommended that they be rotated so that one of the electrodes does not sit on the bottom of the pipe. This helps prevent problems from sediment covering the electrode. Note that on the unit in Figure 2, the magnetic field is generated by an insert unit into the pipeline. Some manufacturers install the coils to generate the magnetic field outside of the spool piece.

${ }^{1}$ Reference to any specific product does not imply an endorsement or recommendation of use by the authors. The product names are included for completeness and clarifications in this paper. 


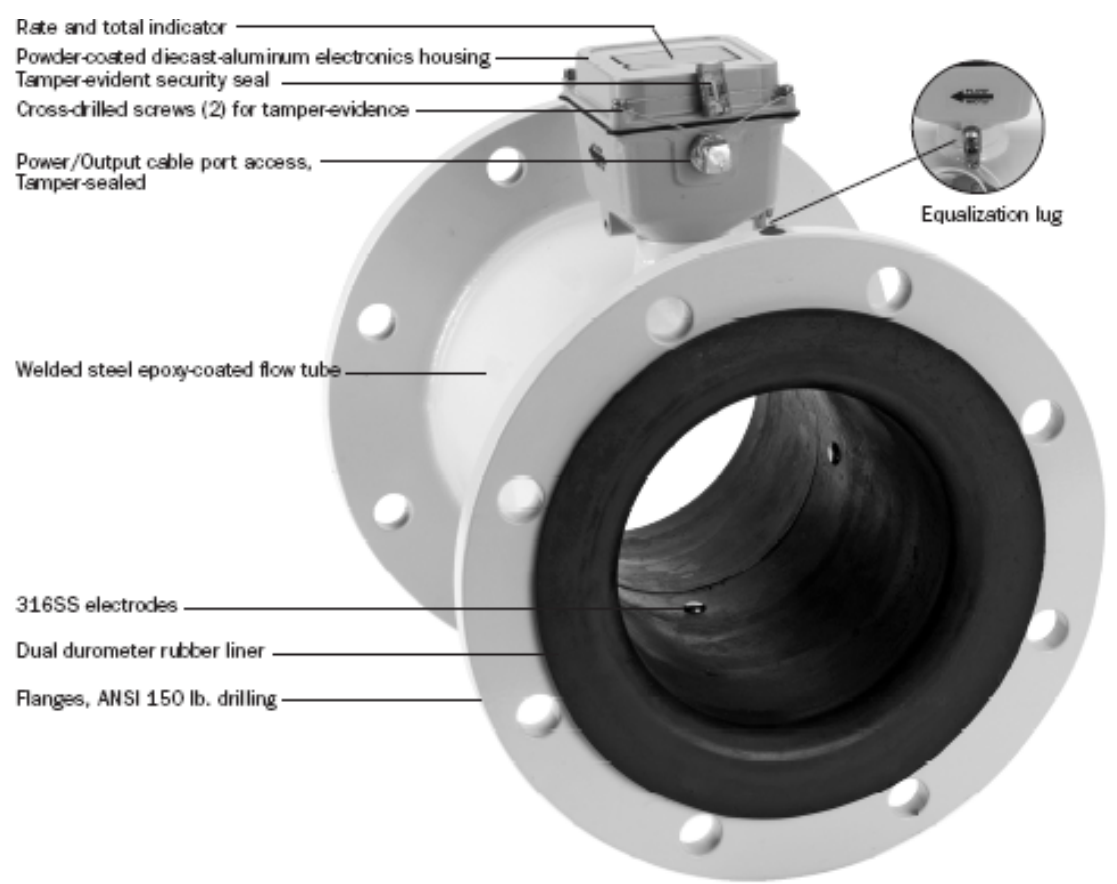

Figure 2. View of typical magnetic meter (SeaMetrics 2009)

\section{Advantages of Magnetic Meters}

- Highly accurate even with some flow disturbance.

- No headloss caused by meter.

- Not impacted by trash, sediment, or sand.

- Measures a wide range of velocity. This is a key criterion in areas that have seasonal high flows combined with very low flows.

- Instantaneous and volumetric totalizing capability.

- Measurement accuracy is NOT affected by varying canal water levels.

- Minimal maintenance required.

- Temperature of the liquid has no effect on accuracy.

\section{Disadvantages of Magnetic Meters}

- Cost is a major constraint. Recently the cost has dropped dramatically, but this is still the most expensive option in some cases.

- Pipe must be full (as is the case in most agricultural applications).

- Installation into existing sites is often difficult and expensive.

- Sensitivity to turbulence.

\section{Turbulence and Magnetic Meters}

Magnetic meters have been considered particularly tricky for pumping plants and turnouts, because of the meter's sensitivity to turbulence. For example, one of the main problems associated with turnouts is the turbulence that occurs just downstream of the gate. Figure 3 shows a typical turnout application with a magnetic meter. 


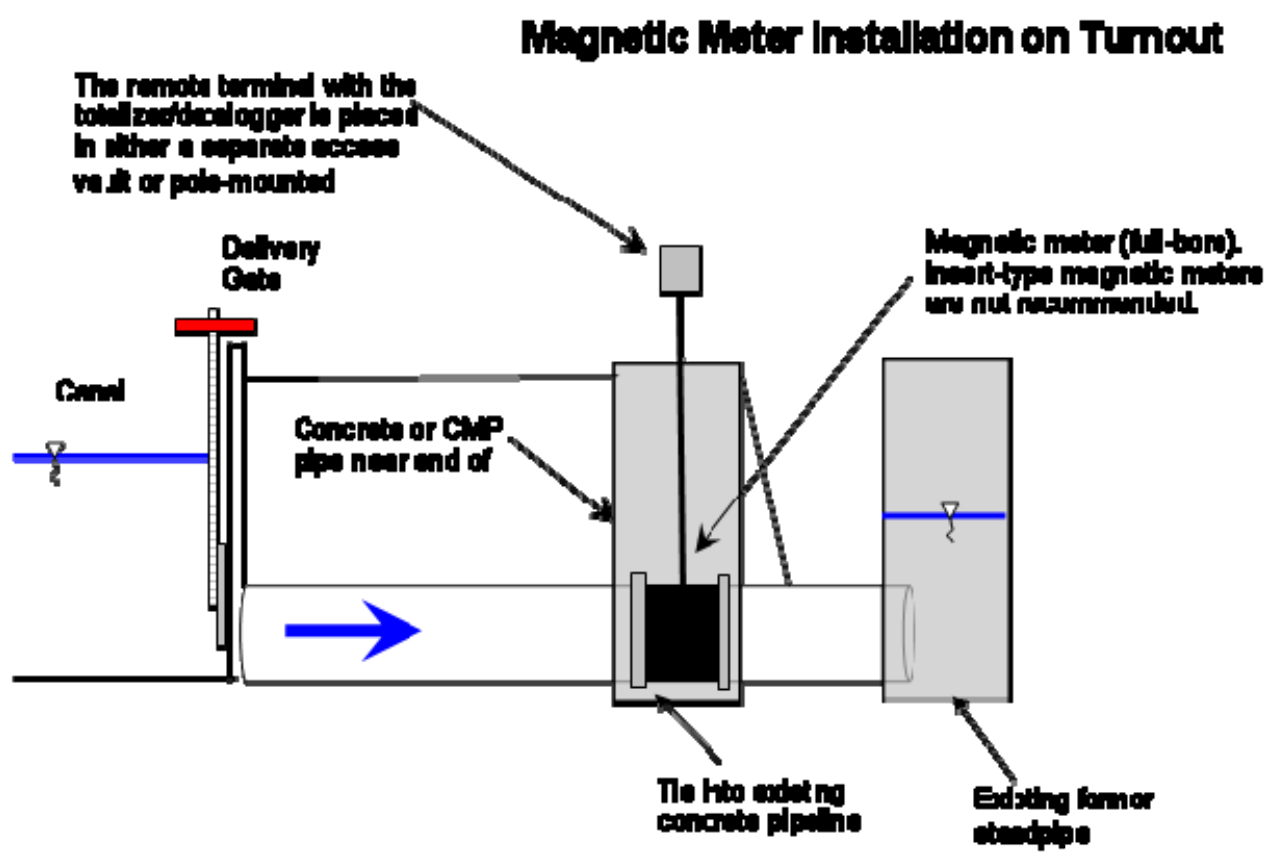

Figure 3. Conceptual sketch of magnetic meter installation for turnouts (not to scale)

In 1998, Hanson and Schwankl published results from non-optimal flow meter testing in their paper Error Analysis of Flowmeter Measurements. Pipeline measurements were taken with different types of flow meters to determine the effects on error resulting from different degrees of turbulence caused by elbows, check valves, and a partially opened check valve. Measurements were made at 2, 5, 10, and 15 pipe diameters downstream from the source of turbulence.

The results from Hanson and Schwankl (1998) indicated that for generally acceptable accuracy with propeller meters, pitot meters, and Doppler meters, measurements should be taken upstream of valves. The tests found that in some circumstances even with as little as 2 or 5 pipe diameters upstream of a flow meter, there were still large errors with all meters under conditions of severe turbulence.

Since most applications require the flow measurement downstream of a valve or turnout gate, manufacturers have recently claimed that their magnetic flow meter technology is now able to work effectively in situations where there are as little as two diameters of pipe length available. ITRC tested several magnetic meters at the Cal Poly Water Resources Facility to investigate these claims.

\section{APPLICATIONS}

Cal Poly Water Resources Facility - Strawberry Application

ITRC conducted test results for six, four-inch SeaMetrics AG2000 Magmeters tested at the Water Resources Facility in August 2010. The purpose of these tests was to verify the performance of the AG2000 magmeters under less than optimal conditions, similar to which is seen on strawberry fields on California's Central Coast. The meters had been installed in 
the field for the last two irrigation seasons. The test results indicate that none of the magmeters exhibit a degradation of accuracy under these conditions.

The magmeters were installed at the Water Resources Facility, in series with a 2-inch pressure regulating valve directly downstream of the magmeter, and a disc filter (Figure 1). The discs were removed from the filter due to immediate clogging.

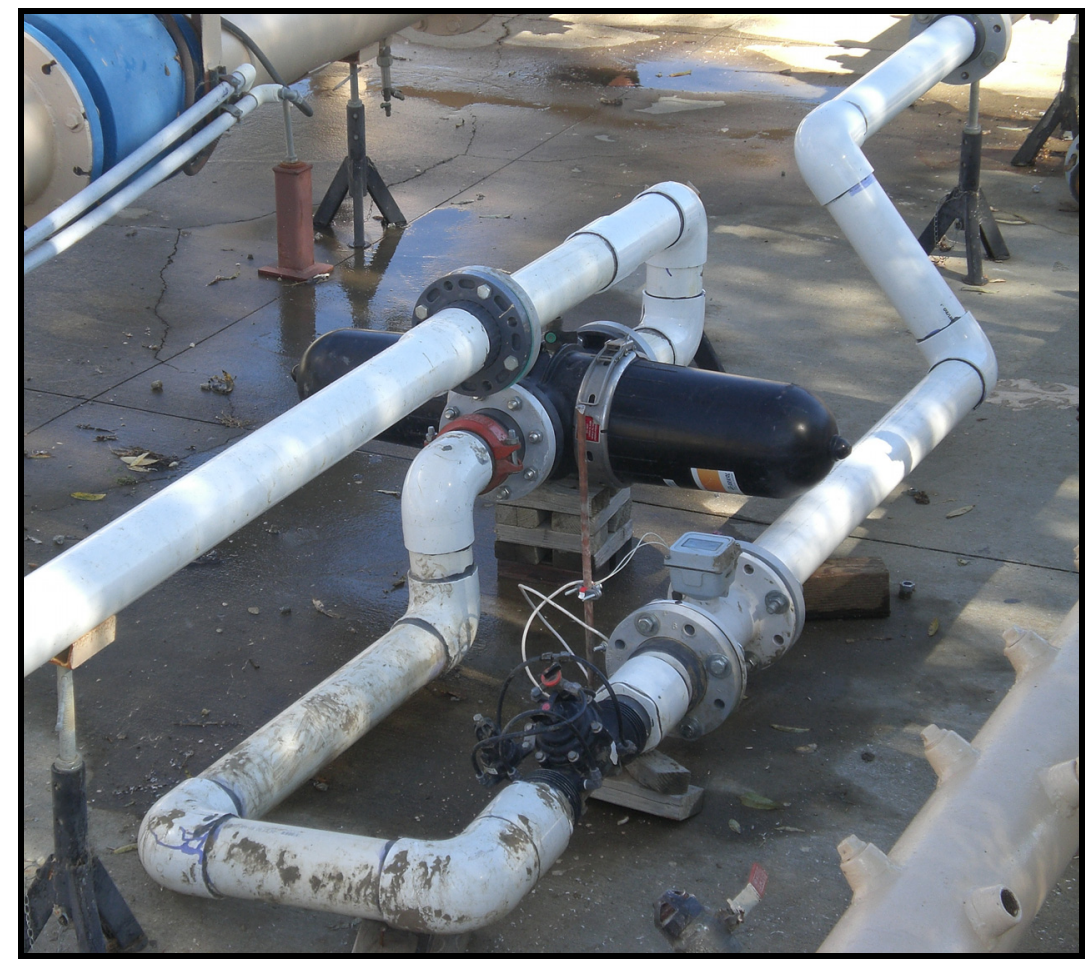

Figure 4. Test configuration for 4-inch magnetic meter

A test was run at four different flow rates, ranging from 80-300 gpm. The results were compared to the control unit for these tests, the ITRC weighing tank. The results from the testing are summarized in Table 1. The percent accuracy shown in the following tables is based off of the formula:

$\%$ Accuracy $=($ Test meter - Control unit $) /$ Control unit 
Table 1: Summary of Grounded Test Results

SeaMetrics AG2000 Magmeters

Cal Poly ITRC Water Resources Facility

\begin{tabular}{|c|c|c|}
\hline Meter \#: 1 & \multicolumn{2}{|c|}{ S/N: 08080373 } \\
\hline $\begin{array}{c}\text { Control Q } \\
\text { (cfs) }\end{array}$ & $\begin{array}{c}\text { Meter Q } \\
\text { (cfs) }\end{array}$ & $\begin{array}{c}\text { Accuracy } \\
\text { (\%) }\end{array}$ \\
\hline 0.462 & 0.46 & -0.17 \\
\hline 0.389 & 0.39 & -0.33 \\
\hline 0.304 & 0.3 & -1.05 \\
\hline 0.194 & 0.19 & -1.23 \\
\hline \multirow{2}{*}{} & AVG & $-\mathbf{- 0 . 6 9}$ \\
\cline { 2 - 3 } & r2 & $\mathbf{0 . 9 9 9 7}$ \\
\hline
\end{tabular}

\begin{tabular}{|c|c|c|}
\hline Meter \#: 2 & \multicolumn{2}{|c|}{ S/N: 9091671 } \\
\hline $\begin{array}{c}\text { Control Q } \\
\text { (cfs) }\end{array}$ & $\begin{array}{c}\text { Meter Q } \\
\text { (cfs) }\end{array}$ & $\begin{array}{c}\text { Accuracy } \\
\text { (\%) }\end{array}$ \\
\hline 0.517 & 0.51 & -0.44 \\
\hline 0.439 & 0.44 & -0.52 \\
\hline 0.363 & 0.36 & -1.18 \\
\hline 0.225 & 0.23 & 1.01 \\
\hline \multirow{3}{*}{} & AVG & $-\mathbf{0 . 2 8}$ \\
\cline { 2 - 3 } & r2 & $\mathbf{0 . 9 9 9 4}$ \\
\hline
\end{tabular}

\begin{tabular}{|c|c|c|}
\hline Meter\#: 3 & \multicolumn{2}{|c|}{ S/N: 9091468 } \\
\hline $\begin{array}{c}\text { Control Q } \\
\text { (cfs) }\end{array}$ & $\begin{array}{c}\text { Meter Q } \\
\text { (cfs) }\end{array}$ & $\begin{array}{c}\text { Accuracy } \\
\text { (\%) }\end{array}$ \\
\hline 0.516 & 0.51 & -0.25 \\
\hline 0.436 & 0.43 & -0.86 \\
\hline 0.372 & 0.37 & -1.17 \\
\hline 0.245 & 0.24 & -0.87 \\
\hline \multirow{3}{*}{} & AVG & $-\mathbf{0 . 7 9}$ \\
\cline { 2 - 3 } & r2 & $\mathbf{0 . 9 9 9 8}$ \\
\hline
\end{tabular}

\begin{tabular}{|c|c|c|}
\hline Meter \#: 4 & \multicolumn{2}{|c|}{ S/N: 9091674 } \\
\hline $\begin{array}{c}\text { Control Q } \\
\text { (cfs) }\end{array}$ & $\begin{array}{c}\text { Meter Q } \\
\text { (cfs) }\end{array}$ & $\begin{array}{c}\text { Accuracy } \\
\text { (\%) }\end{array}$ \\
\hline 0.83 & 0.83 & -0.14 \\
\hline 0.684 & 0.68 & -0.32 \\
\hline 0.572 & 0.57 & -0.28 \\
\hline 0.224 & 0.22 & -1.52 \\
\hline \multirow{3}{*}{} & AVG & $-\mathbf{0 . 5 6}$ \\
\cline { 2 - 3 } & r2 & $\mathbf{1 . 0 0 0 0}$ \\
\hline
\end{tabular}

\begin{tabular}{|c|c|c|}
\hline Meter\#: 5 & \multicolumn{2}{|c|}{ S/N: 9081495 } \\
\hline $\begin{array}{c}\text { Control Q } \\
\text { (cfs) }\end{array}$ & $\begin{array}{c}\text { Meter Q } \\
\text { (cfs) }\end{array}$ & $\begin{array}{c}\text { Accuracy } \\
\text { (\%) }\end{array}$ \\
\hline 0.424 & 0.43 & 1.42 \\
\hline 0.381 & 0.39 & 1.17 \\
\hline 0.334 & 0.34 & 0.73 \\
\hline 0.276 & 0.28 & 0.91 \\
\hline \multirow{3}{*}{} & AVG & $\mathbf{1 . 0 6}$ \\
\cline { 2 - 3 } & r2 & $\mathbf{0 . 9 9 9 4}$ \\
\hline
\end{tabular}

\begin{tabular}{|c|c|c|}
\hline Meter :\#6 & \multicolumn{2}{|c|}{ S/N: 9081496 } \\
\hline $\begin{array}{c}\text { Control Q } \\
\text { (cfs) }\end{array}$ & $\begin{array}{c}\text { Meter Q } \\
\text { (cfs) }\end{array}$ & $\begin{array}{c}\text { Accuracy } \\
\text { (\%) }\end{array}$ \\
\hline 0.46 & 0.46 & -0.7 \\
\hline 0.407 & 0.4 & -0.91 \\
\hline 0.362 & 0.36 & -0.9 \\
\hline 0.308 & 0.31 & -0.17 \\
\hline \multirow{3}{*}{} & AVG & $-\mathbf{0 . 6 7}$ \\
\cline { 2 - 3 } & r2 & $\mathbf{0 . 9 9 6 8}$ \\
\hline
\end{tabular}

\begin{tabular}{|c|c|c|}
\hline Meter \#: 7 & \multicolumn{2}{|c|}{ S/N: 7060672 } \\
\hline $\begin{array}{c}\text { Control Q } \\
\text { (cfs) }\end{array}$ & $\begin{array}{c}\text { Meter Q } \\
\text { (cfs) }\end{array}$ & $\begin{array}{c}\text { Accuracy } \\
\text { (\%) }\end{array}$ \\
\hline 0.462 & 0.46 & -1.13 \\
\hline 0.416 & 0.41 & -0.91 \\
\hline 0.361 & 0.36 & -0.63 \\
\hline 0.294 & 0.29 & -0.72 \\
\hline \multirow{2}{*y}{} & AVG & $-\mathbf{0 . 8 5}$ \\
\cline { 2 - 3 } & r2 & $\mathbf{0 . 9 9 9 1}$ \\
\end{tabular}

Cal Poly Water Resources Facility - Vertical Turbine Application

Tests were conducted over a flow range of approximately 0.8 to $115 \mathrm{lps}$ (12 to $1,800 \mathrm{gpm}$ ) using a second magnetic meter in optimal flow conditions as the control unit. The control unit used for the test was a $30.5 \mathrm{~cm}$ (12-inch) McCrometer Ultra Mag flow meter, which had been calibrated using the weighing tank facility at the Water Resources Facility. ITRC did not attempt to verify the true accuracy of the AG2000 flow meter readings, only the accuracy compared to the control units. 
A magnetic flow meter was mounted on the Water Resources Facility Pump \#2, downstream of a cast-iron concentric reducer, and immediately downstream of a butterfly valve (refer to Figure 5), designated as Test \#1. The retail cost of this $25.4 \mathrm{~cm}$ (10 inch) magnetic meter is $\$ 1,500$ which is comparable to a standard propeller meter. This test configuration was designed to represent the "worst possible conditions imaginable" for an actual irrigation application.

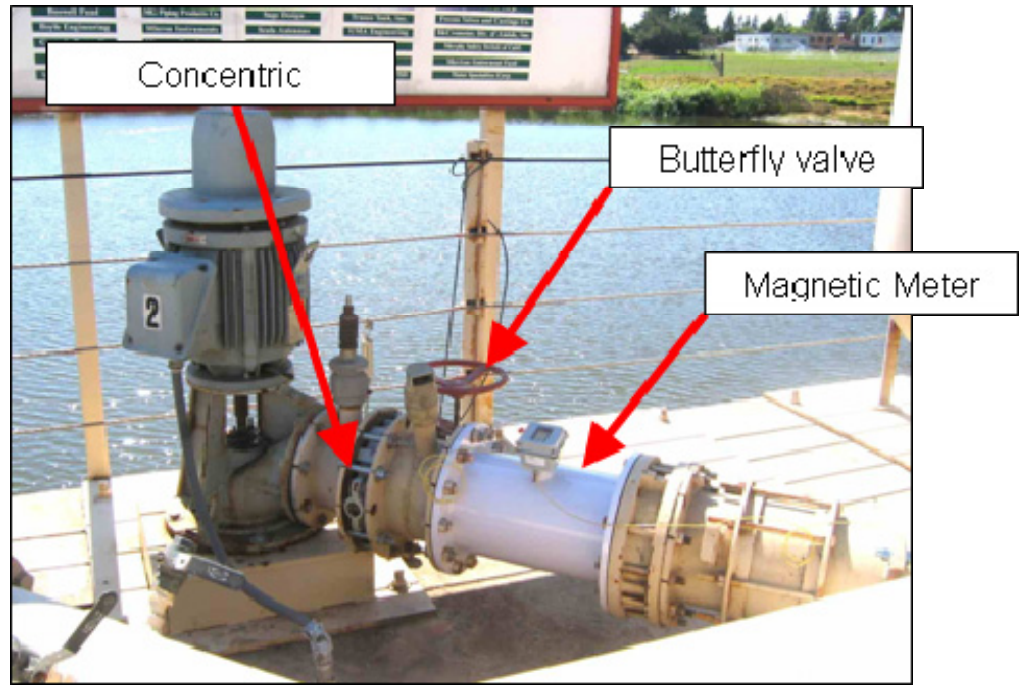

Figure 5. AG2000 test condition for Test \#1 on 10 -inch $(30.5 \mathrm{~cm})$ pipe

Once the initial flow rate was established, turbulence was introduced into the pipeline. The butterfly valves were adjusted during the tests from wide open to $75 \%$ and $90 \%$ closed in Tests \#1 and \#2, respectively. This testing would represent the worst possible case for irrigation applications.

The error analysis of the AG2000 flow meter test results is summarized in Table 2. The accuracy was less than $\underline{\mathbf{+ 2 \%}}$ when the butterfly valve was partially closed, up to $50 \%$. The percent error was more than $-10 \%$ when the butterfly valve was closed more than $75 \%$. This increase in percent error may be attributed to the jetting effect of the cast-iron concentric reducer coupled immediately upstream of the butterfly valve.

By comparison, the results reported by Hanson and Schwankl (1998) for partially closed butterfly valves with a propeller meter mounted two diameters downstream were $\pm 14 \%$ at $42.7 \mathrm{lps}(668 \mathrm{gpm}), \pm 15 \%$ at $73.7 \mathrm{lps}(1,153 \mathrm{gpm})$, and $\pm 2 \%$ for flow rates of $139.9 \mathrm{lps}$ (2,190 gpm). The valve was closed 10 degrees (out of 90 degrees) to provide the throttling effect. Based on the results of their study, it was recommended to always use a six vane straightening arrangement if measuring the flow rate downstream of a throttled butterfly valve.

The test results indicate that the AG2000 Irrigation Magmeter can be installed downstream of partially closed butterfly valves or other sources of turbulence without excessively degrading accuracy. 
Table 2. AG2000 Test Results at Cal Poly ITRC Water Resources Facility

\begin{tabular}{|c|c|c|c|c|c|c|}
\hline Test \# & Valve Position & $\begin{array}{c}\text { Ultra Mag } \\
\text { Flow Rate } \\
\text { (lps) }\end{array}$ & $\begin{array}{c}\text { Ultra Mag } \\
\text { Flow Rate } \\
\text { (gpm) }\end{array}$ & $\begin{array}{c}\text { AG2000 } \\
\text { Flow Rate } \\
\text { (lps) }\end{array}$ & $\begin{array}{c}\text { AG2000 } \\
\text { Flow Rate } \\
\text { (gpm) }\end{array}$ & $\begin{array}{c}\text { Error } \\
(\%)\end{array}$ \\
\hline \multirow{5}{*}{$\begin{array}{c}\text { Test \#1 } \\
25.4 \mathrm{~cm} \\
\text { (10") } \\
\text { meter }\end{array}$} & Open & 114.4 & 1,791 & 116.0 & 1,816 & +1.4 \\
\hline & $50 \%$ closed & 102.1 & 1,597 & 102.4 & 1,603 & +0.4 \\
\hline & $60 \%$ closed & 90.4 & 1,414 & 88.4 & 1,383 & -2.2 \\
\hline & $70 \%$ closed & 81.2 & 1,271 & 72.8 & 1,140 & -6.3 \\
\hline & $75 \%$ closed & 63.4 & 992 & 55.5 & 868 & -12.5 \\
\hline
\end{tabular}

In summary, the test results indicated that under conditions of severe turbulence due to a partially closed butterfly valve, the flow meter readings were not adversely affected. For the $25.4 \mathrm{~cm}$ (10 inch) AG2000 flow meter, a partially closed butterfly valve coupled with a pump discharge caused errors of $1-2 \%$ up to $50 \%$ valve closure. The recorded percent error was generally reduced at the higher flow rates.

\section{CONCLUSION}

The test results completed by the ITRC indicate that the magnetic meter tested can be installed downstream of partially closed butterfly valves or other sources of turbulence without excessively degrading accuracy. Additionally, the magnetic meter is able to provide accurate readings to within $\pm 2 \%$, which is well within the limits expected for agricultural delivery. The costs of these units have also decreased to the point where they are competitive with traditional devices that cannot handle the turbulence associated with some irrigation applications. The accuracy of the devices fits well within the parameters set up by the SB7x7 guidelines developed by the DWR.

\section{REFERENCES}

Hanson, B.R., and Schwankl, L.J. 1998. "Error Analysis of Flowmeter Measurements." J. Irrig. and Drain. Engrg., ASCE 124(5), 248-256.

SeaMetrics, Inc. 2009. "Instructions: AG2000 Irrigation Magmeter." http://www.seametrics.com/flow meter/agAG.html

OMEGA. 2009. Engineering Technical Reference, "Introduction to Magnetic Flow Meters." http://www.omega.com/prodinfo/magmeter.html 